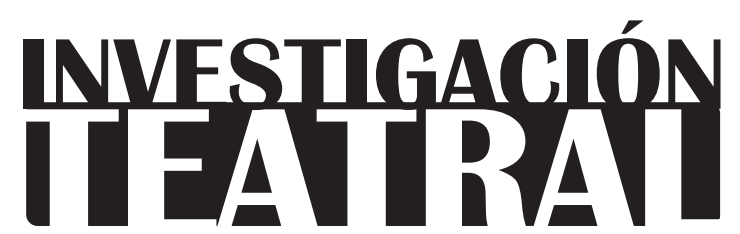

Revista de artes escénicas y performatividad

Vol. 12, Núm. 19

abril-septiembre 2021

Segunda época

ISSN impreso: $1665-8728$

ISSN electrónico: 2594-0953

Universidad Veracruzana
Reseña de libro

Escrituras del silencio.

Figuras, secretos, conspiraciones $y$

diseminaciones de una

dramaturgia de la danza, de Roberto Fratini

Paulina María López Vega*

Recibido: 02 de diciembre de 2020

Aceptado: 09 de febrero de 2021

Doi: $10.25009 /$ it.v12i19.2663 


\section{Escrituras del silencio. Figuras, secretos, conspiraciones y diseminaciones de una dramaturgia de la danza, de Roberto Fratini}

Fratini Serafide, Roberto. Escrituras del silencio. Figuras, secretos, conspiraciones y diseminaciones de una dramaturgia de la danza. Ciudad de México: Paso de Gato, 2018, pp. 592. ISBN: 978-607-8584-26-0.

$\mathrm{E}$ n un silencio extendido a 568 páginas de escritura, Roberto Fratini Serafide, a través de la editorial Paso de Gato, con el apoyo del Fondo Nacional para la Cultura y las Artes, ${ }^{1}$ en colaboración con la Universidad de Guadalajara ${ }^{2}$ y el Centro Nacional de Investigación, Documentación e Información Teatral Rodolfo Usigli (CITRU), nos ofrece una compilación de textos que piden ser leídos con una ración adecuada de paciencia. Paciencia, entendida en los mismos términos propuestos por el autor, como una aceptación de "las formas de cosas y eventos capaces de invalidar todo formato previo de la experiencia" (413), y como un repudio hacia la "tentación de entender de inmediato cosas cuyo sentido no será restituido más que a través de latitudes incalculables de tiempo y de vida interior" (ibidem). ${ }^{3}$

Con un prólogo de Víctor Molina (a quien Fratini otorga el crédito de la idea de la compilación), el libro se encuentra conformado por cinco partes que concluyen con formas texturales ${ }^{4}$ nada rigurosas en cuanto al corpus teórico general y cuyos encabezados presumen la figura de estructuras musicales: un preludio, dos interludios, una fuga y

\footnotetext{
A través del Programa de Fomento a Proyectos y Coinversiones Culturales 2017.

A través de la Secretaría de Vinculación y Difusión Cultural.

3 En este caso, el autor refiere concretamente a lo que él nombra como paciencia poética (413-414).

4 El autor habla de la textilidad o la texturalidad versus la textualidad en una conversación con Roger Bernat, definiendo a la primera como una "manera de organizar como entramado el conjunto de los signos que componen el espectáculo"; mientras que para la segunda, solemos referirnos a "algo que puede ser transcrito", y que presenta cierta dimensión de permanencia (ver "Roberto Fratini y Roger Bernat").
} 
un posludio (sic). Los otros 24 subtítulos, distribuidos en Figuras, Silencios, Escrituras, Conspiraciones y Diseminaciones, reúnen parte de la producción publicada e inédita del autor a lo largo de más de una década. ${ }^{5}$

En la solapa podemos leer la nacionalidad italiana de Roberto Fratini, quien deberá contar, para este 2021, con 41 años de edad. Decirlo así resultará sin duda ofensivo para las mentalidades de un mundo "que entroniza a la infancia con enternecimiento mesiánico mientras criminaliza el universo adulto, y que se abandona con un entusiasmo fascista al culto de la juventud como valor supremo" (366), aspecto en el que el autor insistirá a lo largo de su obra como una aguda crítica hacia los mecanismos de producción, distribución y recepción de la danza, el teatro y el performance, principalmente europeos. Importa destacar esto último, ya que en toda la obra no hay ninguna reflexión con la mirada puesta en la esfera latinoamericana y, si acaso, encontraremos en sus fuentes bibliográficas una o dos referencias de estas latitudes. ${ }^{6}$ Escrituras del silencio sale a la venta como el tercer libro publicado por el autor, después de A Contracuento. La danza y las derivas del narrar (2012) y Filosofía de la danza (2015), escrito en coautoría con Magda Polo Pujadas y Bàrbara Raubert, ambos de editoriales españolas.

Dice el poeta Khalil Gibran que "[e]l amor es una palabra luminosa, escrita por mano luminosa, en página luminosa" (30), y definitivamente Escrituras del silencio es un libro de irradiante luminosidad. El autor, a través de un desesperado grito insonoro, exige tanto a artistas, teóricos y audiencias tomar con la seriedad, respeto y compromiso con que atendemos nuestras muertes a esta labor de manufactura humana llamada arte, muy por encima de los márgenes de institucionalidad, inclusividad e incluso performatividad, entendida esta última con fatalidad cuando se le toma como "criterio de todas las verdades" (518) y exigiendo, en cuanto a ella, una revaloración de los términos: presencia, espontaneidad y emergencia. Sus lanzas de palabras puntiagudas y enunciados quiásmicos traspasan, por mencionar algunos, los conceptos de cultura ("orgía plagada de formalidades" -389-), creatividad, danza, dramaturgia, experiencia y teatro.

Puja, a través de un lenguaje que se torna ácido y violento, para dejar de mirar en la danza ese lugar de regocijo hedonista y magia transformadora, la mano salvadora de un

5 Encontramos un texto fechado el año 2006 (precisamente el que ostenta una referencia directa a la Dramaturgia silenciosa, pp. 185-213) y de ahí un salto de cinco años sin producción presentada. El resto de los textos datan del 2011 al 2018 con un énfasis productivo hacia el año 2015, en que aparecen registrados seis subtítulos.

6 La única consideración en este sentido aparece en la página 548 como una Nota para la edición mexicana, en la cual el autor advierte que por cuestiones de espacio, señalará solamente algunos de los protocolos de las Dramaturgias del debate que se encuentran en el documento original. 
mundo que se desquebraja; "de competencias tan [únicas] como para avalar la existencia de una ceguera, de un talón de Aquiles exclusivo del lenguaje" (202) que sólo ella, en sus movimientos, puede subsanar, y en cambio, opta por encontrar en su tan contraargumentada marginalidad un núcleo maravilloso y maldito de esencialidad (176). Danza olvido y huida: "fuerza secreta de lo "ininmportante" (ibídem), donde el cuerpo, como materia inteligente, hace gala de cierta libertad otorgada por la facultad que tiene de ser objeto (165).

La dramaturgia silenciosa será aquella donde se re-negocie la ficción y una renuncia al decir, rebose "de signos que no consiguieron ser palabras porque anhelaban ser más que eso" (195). Propone entonces hablar de ecosistemas de sentido, es decir, "condiciones de respiración, vitalidad y pervivencia de un entorno de signos" (226), un desbordamiento semántico que conlleva incluso al suicidio dramatúrgico: "puede que el sistema enarbolado por el espectáculo se bloquee o se enrede porque es poéticamente necesario producir su parálisis, su aporía; puede, en cambio, que simplemente llegue a la imposibilidad de un final (y, por ende, a un final infinito)" (229). Destrucciones, hundimientos e interrupciones que más que otorgar certezas conlleven al ejercicio de la duda.

Ofrece también un estudio profundo en relación con los dispositivos escénicos, entendidos como estructuras de azar regladas en que el flujo teatral o dancístico es impedido por la noción de un cuerpo pensante en ejecución resolutiva, a saber: el camino como respuesta a la composición laberíntica del dispositivo (Margarit en Fratini 315). Se explaya con sagacidad de juicio en el tema de la participación como la manifestación de cuerpos agente autoexhortados colectivamente a la desinhibición y en exposición al gozo obligado de cierta pornografía cultural: "La experiencia pornográfica se resume fenomenológicamente en la infinita disponibilidad a excitarse por la epifanía de lo obvio y consabido" (384).

No menos controversial resulta el último apartado en que se despliega un listado sui géneris de los, por él denominados, protocolos o dramaturgias del debate: "La dramaturgia básica del debate queda así definida como la simulación de performance sincero en la que un público entrenado a fingirse seguro de sí dialoga con un artista entrenado a fingirse inseguro" (543). Informa el autor que en torno al "proyecto" - que presenta ya 40 diferentes protocolos- existe un equipo de colaboración que se encuentra documentando y aplicando una encuesta, a gran escala, sobre la utilidad y sentido de dichos formatos.

Así, entre crudeza poética y afabilidad satírica, Roberto Fratini va tejiendo la heterogeneidad de su libro al presentar desde un análisis coréutico extenso y complejo de la $D i$ vina comedia, hasta una somera descripción fenomenológica del Harlem Shake. A lo largo de este recorrido aparecerán reflexiones por demás interesantes sobre el Tanztheater de Pina Bausch y la influencia que en ella tuvo el trabajo de Kurt Jooss; el juego simbólico 
entre el cuerpo y la marioneta en Heinrich von Kleist; la estética de Loïe Fuller en el trabajo de la polaca Ola Maciejewska; la producción Voronia (2015) de Marcos Morau; la danza grotesca de Andréane Leclerc en Chrepaka (2014); la compañía china TAO Dance Theatre, fundada por Tao Ye en 2008, a quien el autor considera como "uno de los coreógrafos 'seriales' del primer tramo de siglo" (270); el trabajo de su coterráneo Alessandro Sciarroni, su fascinación por los espejos y el reconocimiento de la destreza como "principal aliada del aquí y del ahora" (282); el hip-hop y sus derivados en los procesos pedagógicos, de legitimación y mediáticos, estos últimos asumidos como su principal potencia y debilidad; la compañía DV8 y su poética maximalista del hard contact; la noción de paisaje en los Conde Torrefiel como el "naufragio de todo lo humano en una trama tupida, borrascosa y festiva de eventos que ya no tienen nada de acontecer verdadero, y de experiencias que ya no tienen nada de cuanto acostumbrábamos llamar vida" (367); el performance happy happy del flash mob y la construcción de pseudo comunidades que sólo existen como espectáculo (502), y sobre dos piezas de la compañía FFF (Friendly Face of Fascism): Pendiente de voto (2012) y Numax-Fagor-Plus (2013) de las que el autor firmó la dramaturgia.

Roberto Fratini, teórico y dramaturgo de acelerado pensamiento ético y ágil vocabulario, hace un llamado urgente a la vitalidad en estos tiempos de posmodernidad en los que la inercia intempestiva de una irremediable caída hace creer que se vuela. ${ }^{7}$ A través de las páginas de sus Escrituras del silencio nos invita a volver utilizables las palabras malo y feo, a buscar hacer formas en vez de seguir el impulso infantil de romper formatos. En fin, diría yo, a transformar lo políticamente incorrecto en todo lo que requiere ser incorrectamente político.

Alguien podría, en suma, estar perdiendo una hora de su último día de vida tragándose nuestras sandeces. Lo sé, es un pensamiento algo tétrico. Pero cuando queramos medir los impredecibles aspectos éticos de nuestra movidas estéticas nos preguntaremos simplemente si no sería sumamente antipático que el fundido a negro de la existencia de alguien se hiciera sobre una imagen terminal de fealdad, de estupidez, de descuido, de arrogancia o de banalidad. Los moribundos son el público más honesto (520).

7 "Adicta a su propio vértigo, insensibilizada por su norma de aceleración y crecimiento incondicional, la posmodernidad recuerda al paracaidista que, a mitad del vuelo, siente que flota mientras sigue precipitando" (365). 
INVESTIGACIÓNTEATRAL

Revista de artes escénicas y performatividad

Vol. 12, Núm. 19

abril-septiembre 2021
Escrituras del silencio

Paulina María López Vega

\section{Fuentes consultadas}

Gibran, Khalil. Arena y espuma. $7^{a}$ ed. México: Sayrols, 1984.

"Fratini Roberto y Roger Bernat-Dramaturgias silenciosas". YouTube, subido por Acción formativa PLATEA, 1 de octubre de 2019, https://www.youtube.com/watch?v=M1gOUNC9-R8, consultado el 1 de diciembre del 2020. 